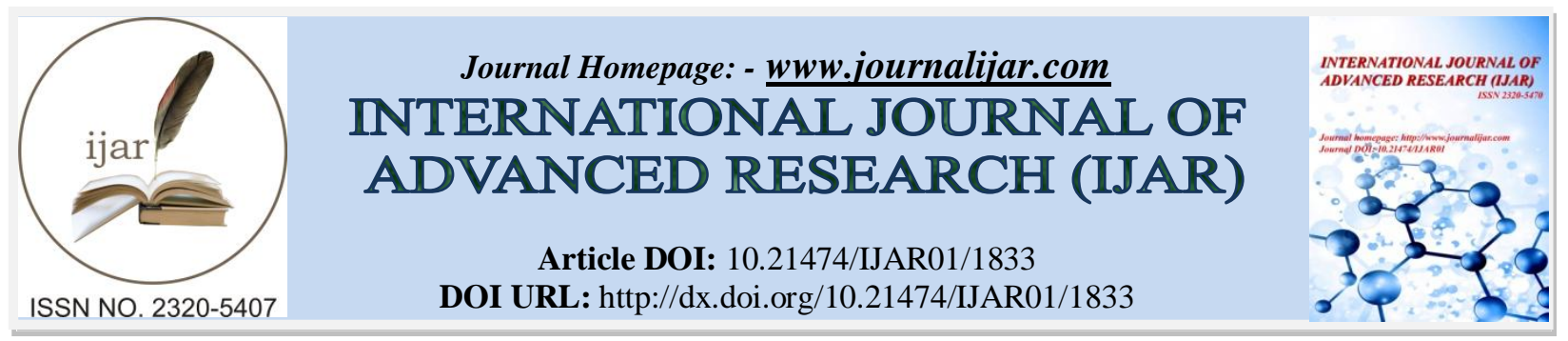

RESEARCH ARTICLE

\title{
STRUCTURAL AND FREQUENCY DEPENDENT DIELECTRIC PROPERTIES OF ZnO NANOPARTICLES AND PANI / ZnO NANOCOMPOSITE BY MICROWAVE-ASSISTED SOLUTION METHOD.
}

\author{
C. Thenmozhi ${ }^{1}$, V. Manivannan ${ }^{1}$, E. Kumar ${ }^{2 *}$ and S. Veera Rethina Murugan ${ }^{3}$. \\ 1. PRIST University, Thanjavur. \\ 2. Dept of Physics, School of Science, Tamil Nadu Open University, Chennai. \\ 3. Dept of Physics, R.S. Govt. College, Thanjavur.
}

\section{Manuscript Info}

Manuscript History

Received: 16 August 2016

Final Accepted: 22 September 2016

Published: October 2016

Key words:-

Microwave assisted synthesis,

Hydrothermal method, $\mathrm{ZnO}$

nanoparticles, XRD, FT-IR, SEM, TEM

and Dielectric properties.

\section{Abstract}

Zinc Oxide nanoparticles were synthesized by microwave assisted hydrothermal method using Zinc Nitrate Hexahydrate $\left(\mathrm{ZnNO}_{3} \cdot 6 \mathrm{H}_{2} \mathrm{O}\right)$ as a starting material. Polyaniline / Zinc Oxide (PANI/ZnO) nanocomposite material was prepared by an in-situ polymerization of aniline in the presence of as-synthesized $\mathrm{ZnO}$ nanoparticles. The structure, morphology and functional group of the synthesized Zinc Oxide nanoparticles and PANI / $\mathrm{ZnO}$ nanocomposites were characterized by X-ray Diffraction (XRD), Transmission Electron Microscopy (TEM), Scanning Electron Microscopy (SEM) and Fourier Transform Infrared Spectroscopy (FTIR). The sharp peaks in the X-ray diffraction pattern indicate that the obtained powder was $\mathrm{ZnO}$ and was crystalline in nature. The crystallite size of the sample were calculated from the full width at half maximum of X-Ray diffraction peaks by using Debye-Scherrer formula and were found to be $45 \mathrm{~nm}$. The absorption peaks in FTIR spectra of PANI / ZnO nanocomposites were slightly shifted to higher wave number than that of pure $\mathrm{ZnO}$, which confirms that there was a strong interaction between polyaniline and Zinc Oxide nanoparticles. The TEM images revealed the uniform distribution of the $\mathrm{ZnO}$ nanoparticles in the PANI matrix. Dielectric studies of $\mathrm{ZnO}$ nanoparticles show the frequency dependent dielectric behaviour of $\mathrm{ZnO}$ nanoparticles. Results reveals that the dielectric constant decrease with the increasing frequency whereas the a.c conductivity of the sample increases with the increase in frequency.

Copy Right, IJAR, 2016,. All rights reserved.

\section{Introduction:-}

$\mathrm{ZnO}$ is a semiconducting oxide material having wide band gap of $3.37 \mathrm{eV}$ at room temperature, which exhibits excellent optical and electrical properties. Due to its physical \& chemical properties, zinc oxide is used in various applications such as photo catalysis, UV protection, solar cell and gas sensor applications. It has been widely used for its catalytic, electrical, optoelectronic and photochemical properties [1-4]. So many techniques are available for the synthesis of $\mathrm{ZnO}$ nanoparticles, namely, hydrothermal synthesis [5], physical vapour deposition [6], electrochemical deposition [7], chemical vapour deposition [8], pulsed laser deposition [9], microwave assisted 
synthesis [10] and thermal evaporation [11]. Since, microwave assisted synthesis is a rapid technique and also cost effective compared to other methods, this method is chosen for producing $\mathrm{ZnO}$ nanoparticles. Zinc oxide ( $\mathrm{ZnO}$ ) is a common material that is readily used in semiconductor fabrication especially in solar cells and gas sensors due to its special properties. Zinc oxide, a versatile semiconductor material has been attracting attention because of the commercial demand for optoelectronic devices operating at blue and ultraviolet regions [12].

\section{Experimental:-}

Materials and Characterization Techniques:-

All the chemicals involved in this microwave assisted method were used as received from the chemical suppliers without any further purification and processing. Aniline (99.5\%), Zinc Nitrate Hexahydrate $\left(\mathrm{ZnNO}_{3} \cdot 6 \mathrm{H}_{2} \mathrm{O}\right)$, Sodium Hydroxide $(\mathrm{NaOH})$ and Ethylene Glycol were procured from E. Merck and Ammonium persulfate (98\%) was purchased from Hi-media and used as received. All the chemicals were of analytical grade and solutions were prepared with double distilled water. Aniline monomer was distilled using cubic condenser for purification.

The prepared $\mathrm{ZnO}$ nanoparticles were characterized by X-Ray Diffraction technique (XRD) and Scanning Electron Microscope (SEM) to find the structure and morphology Crystallographic studies were carried out using a X-Ray diffractometer (Brucker D8 with Nickel filtered $\mathrm{Cu}-\mathrm{K} \alpha$ radiation), in the scanning range of $2 \theta$ from $10^{\circ}-80^{\circ}$ using $\mathrm{Cu}-\mathrm{K} \alpha$ radiations of wavelength $1.5406 \AA$. SEM images of the sample were recorded using the model HITACHI SEM, to study the morphology of the samples and their elemental analysis. HRTEM micrographs of the prepared samples were taken using the Model JEOL - J2000. FT-IR spectra of the sample were recorded in the range of 400 $4000 \mathrm{~cm}^{-1}$ using Shimadzu 8400S FT-IR Spectrometer.

Synthesis of ZnO Nanoparticles - Microwave Assisted synthesis:-

Zinc Nitrate Hexahydrate $\left(\mathrm{ZnNO}_{3} \cdot 6 \mathrm{H}_{2} \mathrm{O}\right)$ and Sodium hydroxide $(\mathrm{NaOH})$ were taken in 1:4 molar ratio and dissolved completely in de-ionized water separately. Then the dissolved $\mathrm{ZnNO}_{3} \cdot 6 \mathrm{H}_{2} \mathrm{O}$ was added with Ethylene Glycol. Further, $\mathrm{NaOH}$ solution was added drop wise into the above mixture under vigorous stirring. Then the prepared mixture solution was kept in the microwave oven $(900 \mathrm{~W}, 2450 \mathrm{MHz})$ for about 30 minutes. Finally, the as-prepared sample was centrifuged several times in double distilled water, ethanol and dried at $150{ }^{\circ} \mathrm{C}$ for 24 hours, resulting in the formation of $\mathrm{ZnO}$ nanoparticles.

\section{Synthesis of PANI / ZnO Nanocomposites:-}

To prepare Polyaniline / $\mathrm{ZnO}$ nanocomposite, Aniline was injected into $2 \mathrm{M}$ HCL containing different wt $\%$ of $\mathrm{ZnO}$ nanoparticles under ultrasonic action to reduce the aggregation of $\mathrm{ZnO}$ nanoparticles. After $12 \mathrm{hrs}$, Ammonium Peroxydisulphate as an oxidant(APS), was dropped into the solution with constant stirring for $10 \mathrm{~min}$. The polymerization was allowed to proceed for $3 \mathrm{hrs}$ at $30^{\circ} \mathrm{C}$. Reaction mixture was filtered and washed with $2 \mathrm{M} \mathrm{HCL}$ and de- ionized water and then dried at $90^{\circ} \mathrm{C}$ for $12 \mathrm{hrs}$ in vacuum. PANI / $\mathrm{ZnO}$ nanocomposite with fine tint green colour was obtained.

\section{Results and Discussion:-}

\section{X-ray Diffraction technique (XRD):-}

The XRD pattern of pure $\mathrm{ZnO}$ nanoparticles is shown in Figure 1a. The XRD result shows that the sharp and the well-defined diffraction peaks formed at $33^{\circ}$ and $58.7^{\circ}$ confirms the formation of $\mathrm{ZnO}$ nanoparticles and also indicate the good crystallinity of synthesized material. The characteristics peaks of $\mathrm{ZnO}$ formed at $33^{\circ}, 45.6^{0}, 58.7^{0}$, $69^{\circ}$ and $73^{\circ}$ corresponds to the miller indices $\left(\begin{array}{lll}0 & 0 & 2\end{array}\right),\left(\begin{array}{lll}1 & 0 & 2\end{array}\right),\left(\begin{array}{lll}1 & 1 & 0\end{array}\right),\left(\begin{array}{lll}2 & 0 & 1\end{array}\right)$ and $\left(\begin{array}{lll}0 & 0 & 4\end{array}\right)$ respectively, which can be indexed with hexagonal phase(JCPDS Card No. 80-0075)[13]. The crystalline size of ZnO nanoparticles was calculated using the value of FWHM from the most intense XRD peaks as around $45 \mathrm{~nm}$ by using Scherrer formula(1) [14].

$$
\mathrm{D}=\frac{K \lambda}{\beta \cos \theta} \quad(\mathrm{nm})
$$

where $D$ is the crystallite size, $K$ is the shape factor( $(0.94), \lambda$ is the wavelength of $X$-rays $\left(\lambda=1.54059 A^{0}\right), \beta$ is the full width at half maximum(FWHM) of the diffraction peaks and $\theta$ is the angle of diffraction. The XRD pattern of PANI / $\mathrm{ZnO}$ nanocomposite (Figure 2a) has a peak at $2 \theta=25^{\circ}$ belongs to PANI, representing the amorphous structure with low crystallinity. The XRD patterns of PANI/ZnO nanocomposite include the characteristic peaks of 
both PANI and $\mathrm{ZnO}$ with the crystalline structure of hexagonal wurtzite, which confirms the formation of nanocomposite with lower crystallinity $[15,16 \mathrm{a}, \mathrm{b}, \mathrm{c}]$.
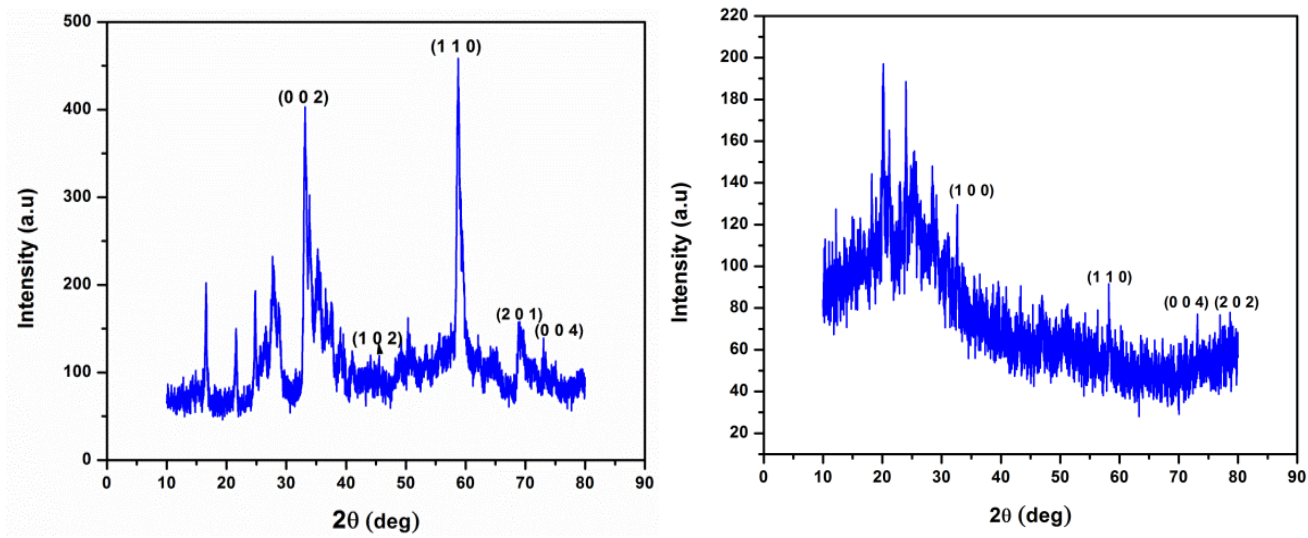

Figure 1a:- XRD pattern of ZnO NPs

Figure 1b:- XRD pattern of PANI/ ZnO Nanocomposite:-
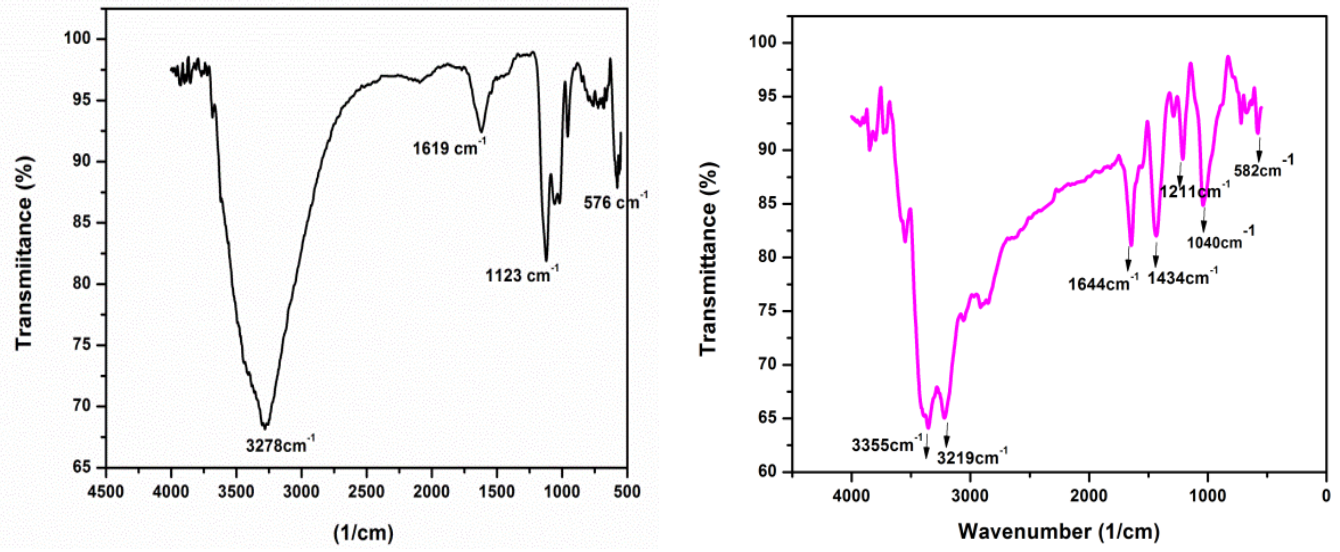

Figure 2a:- FT-IR spectra of ZnO NPs

Figure 2b:- FT-IR spectra of PANI/ ZnO Nanocomposite

\section{FT-IR Spectroscopy:-}

The FT-IR spectra of $\mathrm{ZnO}$ nanoparticles and PANI / ZnO nanocomposite synthesized by microwave assisted hydrothermal method are shown in Figures $2 \mathrm{a}$ and $2 \mathrm{~b}$. The peak at low wave number region of $576 \mathrm{~cm}^{-1}$ is assigned to $\mathrm{ZnO}$ group $[17,18]$. The sharp peak at $1123 \mathrm{~cm}^{-1}$ is due to $\mathrm{C}-\mathrm{H}$ plane bending vibration[19]. The band appears at $1619 \mathrm{~cm}^{-1}$ may be attributed to $\mathrm{C}=\mathrm{C}$ Stretching mode of quinoid ring[20]. The peak at $3278 \mathrm{~cm}^{-1}$ is due to the absorption of water during the preparation of IR pellet[21].

Table 1.2:- Functional group analysis for $\mathrm{ZnO}$ nanoparticles.

\begin{tabular}{|c|c|}
\hline $\begin{array}{c}\text { Wave number } \\
\text { cm-1 }\end{array}$ & Assignments \\
\hline $\mathbf{3 2 7 8}$ & Absorption of water \\
\hline $\mathbf{1 6 1 9}$ & $\mathrm{C}=\mathrm{C}$ Stretching mode of quinoid ring \\
\hline $\mathbf{1 1 2 3}$ & $\mathrm{C}-\mathrm{H}$ plane bending vibration \\
\hline $\mathbf{5 7 6}$ & $\mathrm{ZnO}$ group \\
\hline
\end{tabular}

Table 1.3:- Functional group analysis for PANI / $\mathrm{ZnO}$ Nanocomposites.

\begin{tabular}{|c|l|}
\hline Wave numbers $\left(\mathbf{c m}^{-1}\right)$ & \multicolumn{1}{|c|}{ Assignments } \\
\hline $\mathbf{3 3 5 5}$ & N-H band stretching vibration \\
\hline $\mathbf{3 2 1 9}$ & Hydrogen bonded NH bond \\
\hline $\mathbf{1 6 4 4}$ & Benzoid ring stretching \\
\hline $\mathbf{1 4 3 4}$ & $\mathrm{C}^{-C}$ Stretching in quinoid, C-H bending in benzonoid ring \\
\hline $\mathbf{1 0 4 0}$ & $\mathrm{SO}^{3-}$ vibration \\
\hline $\mathbf{5 8 2}$ & $\mathrm{C}=\mathrm{C}$ Stretching mode of quinoid rings \\
\hline
\end{tabular}




\section{SEM Analysis:-}

Figure 3a.shows the SEM micrograph of the pure $\mathrm{ZnO}$ nanoparticles synthesized by microwave assisted hydrothermal method. It can be observed that nanosized $\mathrm{ZnO}$ particles are formed as nanoclusters. From the SEM image of composite PANI / ZnO Nanocomposite (Figure 3b), it is observed that ZnO nanoparticles are surrounded by polyaniline matrix and hence it appears as agglomerated macromolecules.

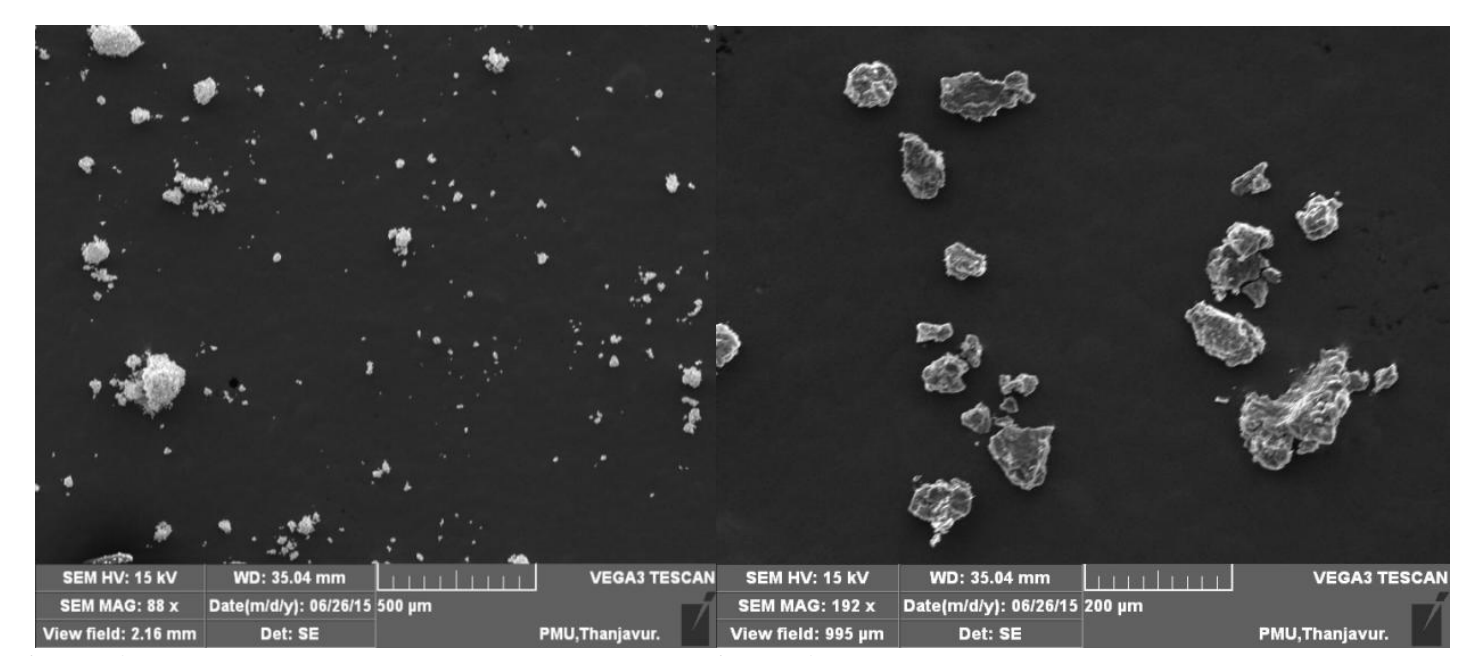

Figure 3a:- SEM image of $\mathrm{ZnO} \mathrm{NPs}$

Figure 3b:- SEM image of PANI / ZnO Nanocomposite

\section{Microstructural properties by HRTEM and SAED pattern:-}

The morphology and particle size of Zinc Oxide nanoparticles were observed using HRTEM micrograph (Figure. 4a). These particles with particle size of 50nm were observed. The particle size of $\mathrm{ZnO}$ nanoparticles was observed as $50 \mathrm{~nm}$ and it is same for PANI / $\mathrm{ZnO}$ nanocomposites. The presence of rod-like shaped PANI / $\mathrm{ZnO}$ nanocomposites was observed from HRTEM micrograph. The particle size observed from HRTEM micrograph matches with the particles size calculated from the XRD investigation. These results confirm the formation of crystalline Zinc Oxide nanoparticles. The corresponding SAED pattern of ZnO nanoparticles is shown in Figure 4b. SAED pattern provides rings made up of bright spots, denotes the crystalline nature of the prepared $\mathrm{ZnO}$ nano particles.

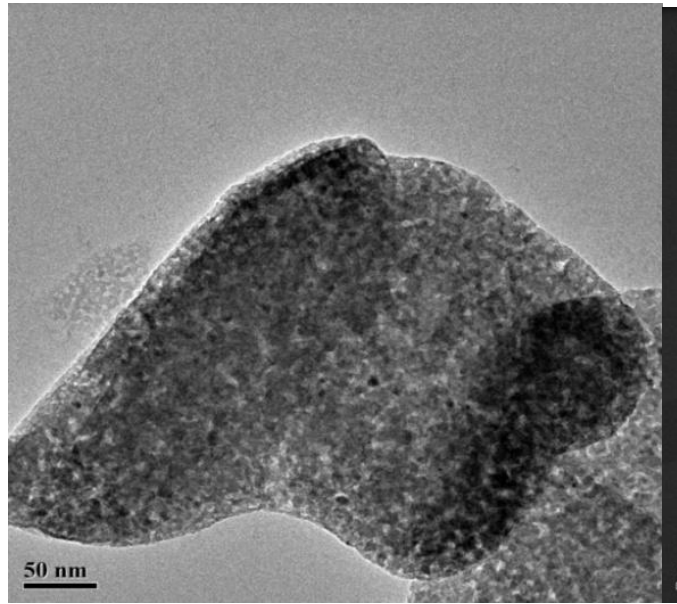

Figure 4a:- HRTEM image of Pure ZnO NPs

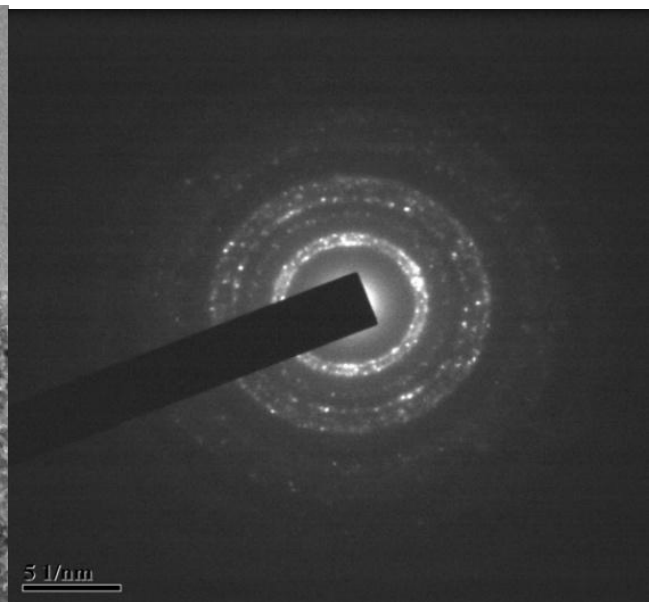

Figure 4b:- SAED pattern of $\mathrm{ZnO} \mathrm{NPs}$ 


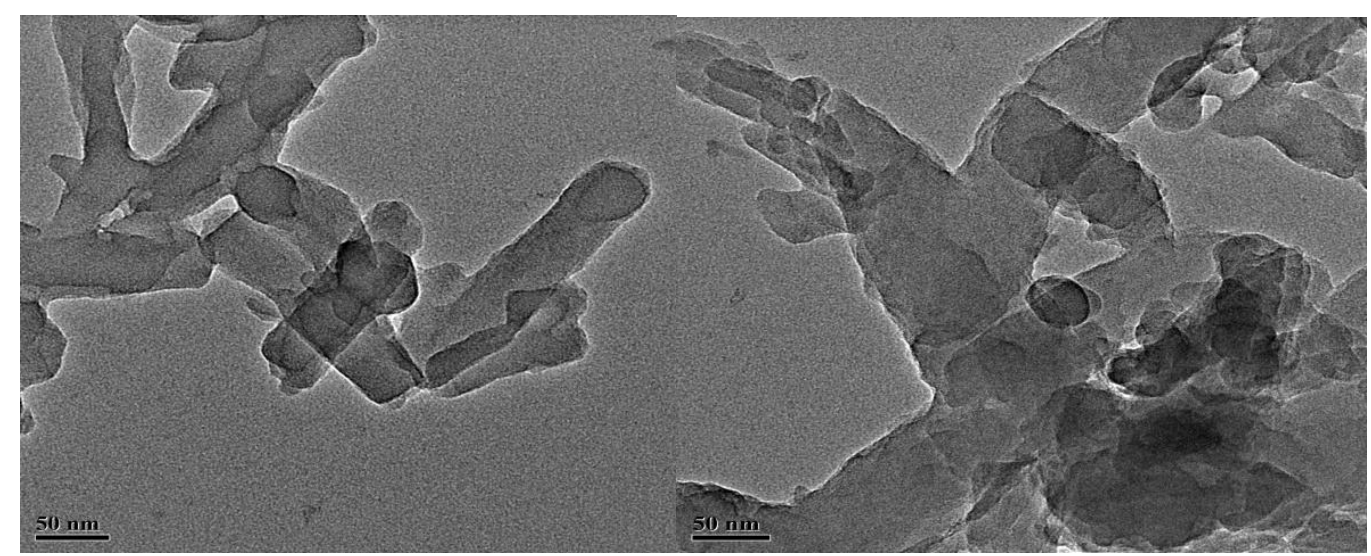

Figure 4a:- HRTEM micrograph of PANI / ZnO Figure 4b:- SAED pattern of PANI / ZnO

\section{Electrical studies:-}

\section{Determination of AC conductivity of $\mathrm{ZnO}$ Nanoparticles:-}

The dielectric properties of $\mathrm{ZnO}$ Nanoparticles can be explained as a function of frequency of the applied electric field and temperature. Figure $5 \mathrm{a}$ and $5 \mathrm{~b}$. shows the variation of ac conductivity with varying frequency for $\mathrm{ZnO}$ nanoparticles and PANI / $\mathrm{ZnO}$ at different temperatures. The ac conductivity of $\mathrm{ZnO}$ Nanoparticles was calculated using the formula,

$$
\sigma_{\mathrm{ac}}=\boldsymbol{\varepsilon}_{0} \boldsymbol{\varepsilon}_{\mathbf{r}} \omega \tan \delta
$$

where $\varepsilon_{0}$ is the permittivity of free space $\left(8.85 \times 10^{-12}\right.$ Farad/metre), $\boldsymbol{\varepsilon}_{\mathrm{r}}$ is the dielectric constant, $\omega(2 \pi \mathrm{f})$ is the angular frequency and tan $\delta$ is the loss factor. It is observed from the figure that the ac conductivity remains almost constant upto $1 \mathrm{KHz}$. Above $1 \mathrm{KHz}$, it increases gradually upto $40 \mathrm{KHz}$ and then increases rapidly from $40-620$ $\mathrm{KHz}$. As $\mathrm{T}$ increases, $\sigma_{\mathrm{ac}}$ decreases. The result revealed that $\mathrm{ZnO}$ nanoparticles shows frequency dependence behaviour and the temperature independence behaviour of conductivity.

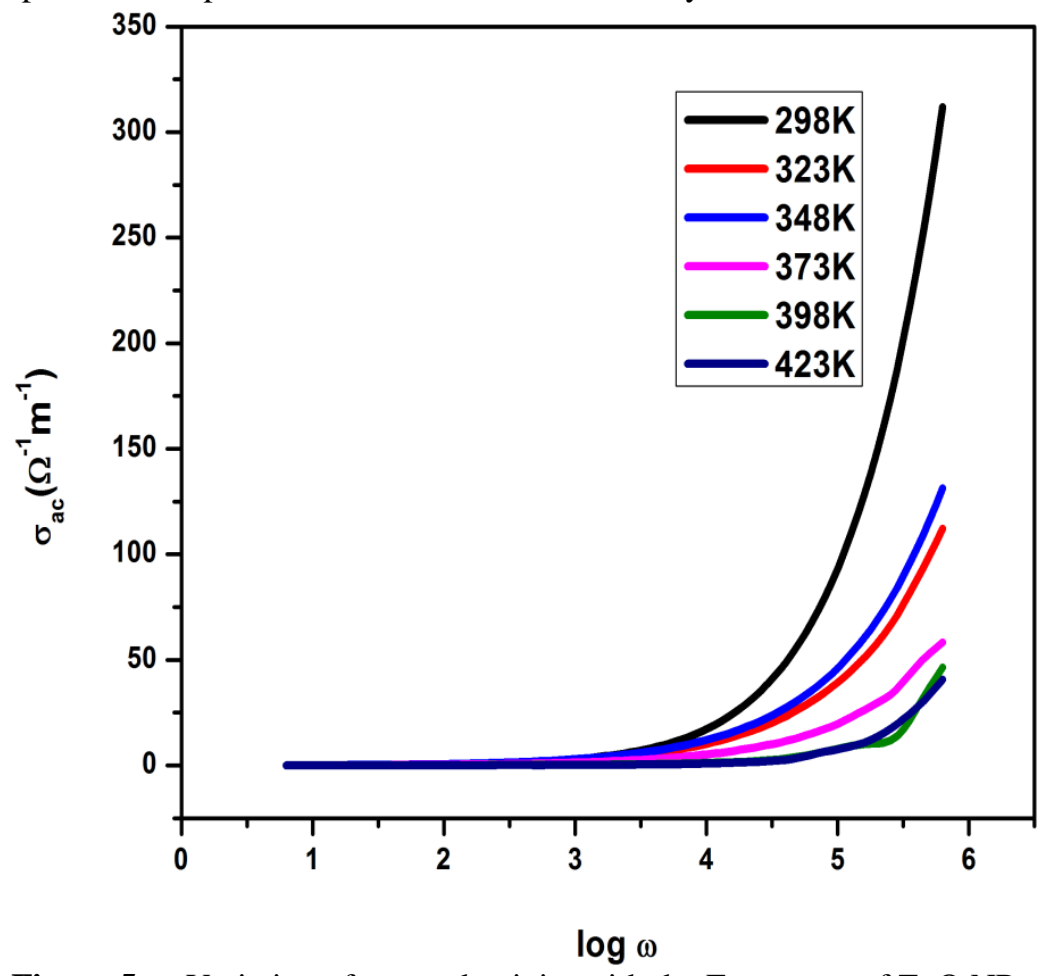

Figure 5a:- Variation of ac conductivity with the Frequency of ZnO NPs. 


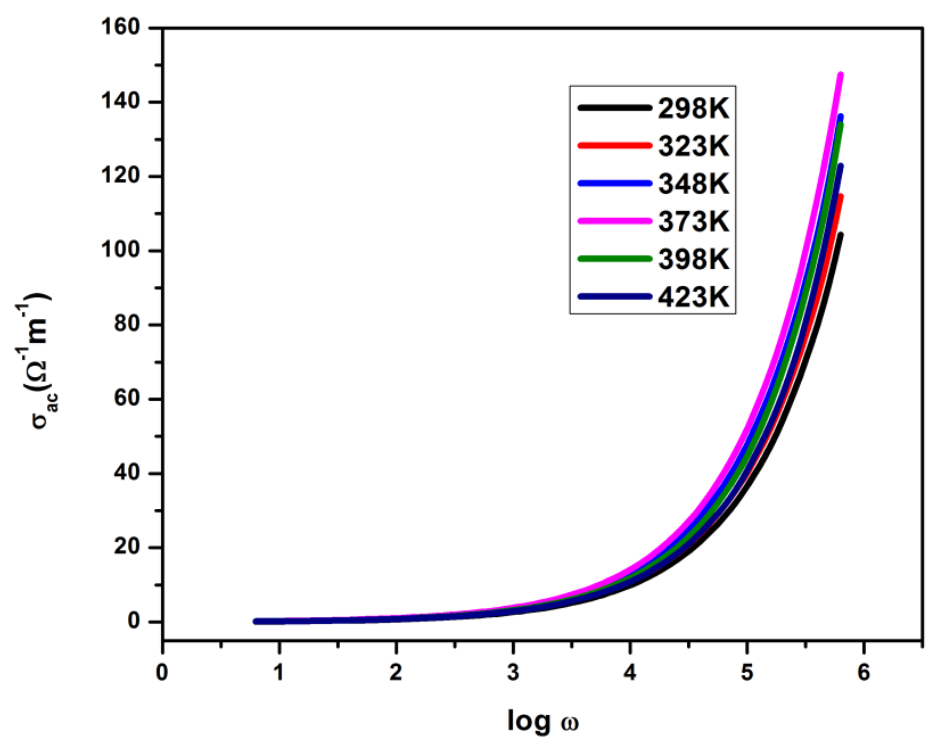

Figure 5b:- Variation of ac conductivity with the Frequency of PANI / ZnO nanocomposite

\section{Dielectric constant of ZnO Nanoparticles:-}

Figure $6 \mathrm{a} \& \mathrm{~b}$ shows the variation of dielectric constant $\left(\boldsymbol{\varepsilon}_{\mathbf{r}}\right)$ with varying frequency in the range of $10 \mathrm{~Hz}-620 \mathrm{KHz}$. The $\varepsilon_{\mathbf{r}}$ decreases faster at lower frequency and slowly at higher frequency. The frequency dependence of electrical properties shows that the dielectric constant $\boldsymbol{\varepsilon}_{\mathrm{r}}$ decreases due to the increase of ac conductivity with increasing frequency. The rapid decrease of $\boldsymbol{\varepsilon}_{\mathrm{r}}$ in the low frequency region was due to space-charge contribution.
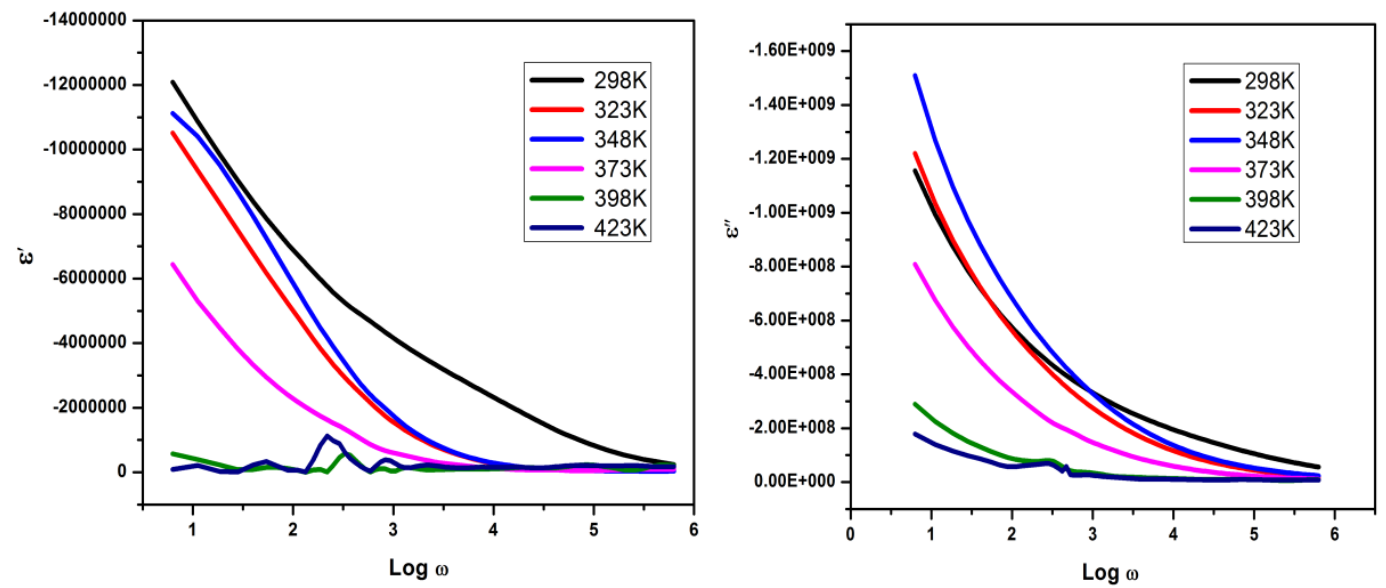

Figure 6:- Frequency dependence of dielectric constant(real \& Imaginary) of ZnO NPs

\section{Conclusion:-}

$\mathrm{ZnO}$ Nanoparticles were prepared using a microwave assisted hydrothermal method. The XRD analysis confired that pure $\mathrm{ZnO}$ nanoparticles were formed in this method. Crystallite size for $\mathrm{ZnO}$ nanoparticles synthesized in this method was found to be $50 \mathrm{~nm}$. The results obtained from TEM studies exactly matches with that of XRD results, which confirmed the formation of $\mathrm{ZnO}$ nanoparticles. FT-IR analysis also confirmed the formation of Zinc Oxide nanoparticles. XRD and FTIR of PANI / ZnO nanocomposite revealed that PANI undergoes interaction with $\mathrm{ZnO}$ Nanoparticles which are embedded in polymer matrix. SEM and TEM micrograph shows the uniform distribution of $\mathrm{ZnO}$ Nanoparticles in PANI / $\mathrm{ZnO}$ nanocomposite. Dielectric studies of $\mathrm{ZnO}$ nanoparticles and PANI / $\mathrm{ZnO}$ nanocomposite shows the frequency dependence dielectric behavior of $\mathrm{ZnO}$ nanoparticles. Results reveals that the dielectric constant decrease with the increasing frequency whereas the a.c conductivity of the sample increases with the increase in frequency. The decrease of dielectric constant $\boldsymbol{\varepsilon}_{\mathrm{r}}$ was due to the increase of ac conductivity with increasing frequency. The rapid decrease of the dielectric constant $\left(\boldsymbol{\varepsilon}_{\mathrm{r}}\right)$ in the low frequency region was attributed to space-charge contribution. 


\section{References:-}

1. Wang, ZL, Zinc oxide nanostructures: growth properties and applications. J. Phys. Condens. Matter. 16, 829858 (2004).

2. Brida, D, Fortunato, E, Ferreira, I, Aguas, H, Martins, R: New insights on large area flexible position sensitive detectors. J. Non-Cryst. Solids. 299, 1272-1276 (2002).

3. Ashour, A, Kaid, MA, El-Syed, NZ, Ibrahim, AA: Physical properties of $\mathrm{ZnO}$ thin films deposited by spray pyrolysis technique. Appl. Surf. Sci. 252, 7844-7848 (2006).

4. Suchea, M, Christoulakis, S, Moschovis, K, Katsarakis, N, Kiriakidis, G, ZnO transparent thin films for gas sensor applications. Thin Solid Films. 515, 551-554 (2006).

5. Kajbafvala, A, Shayegh, M. R.; Mazloumi, M.; Zanganeh, S.; Lak, A.; Mohajerani, M. S.; $\quad$ Sadrnezhaad, S. K.; J. Alloys Compd. 2009, 469, 293.

6. Hejazi, S. R.; Madaah Hosseini, H. R.; Sasani Ghamsari, M.; J. Alloys. Compd. 2008, 455353.

7. Jiang, H.; Hu, J. Q.; Gu, F.; Li, C. Z.; J. Alloys Compd. 2009, 478, 550.

8. Yousefi, R.; Kamaluddin, B.; J. Alloys. Compd. 2009, 479, 11.

9. Wang, X. H.; Liu, S.; Chang, P.; Tang, Y.; Phys. Lett. A, 2008, 372, 2900.

10. Bacaksiz, E.; Yılmaz, S.; Parlak, M.; Varilci, A.; Altunbas, M.; J. Alloys Compd. 2009, 478, 367.

11. Yan, H. W.; Hou, J. B.; Fu, Z. P.; Yang, B. F.; Yang, P. H.; Liu, K. P.; Wen, M. W.; Chen, Y. J.; Li., F. Q.; Mater. Res. Bull. 2009, 44, 1954.

12. Shin. W. C., M. S. Wu, and J. Cryst. Growth vol. 137, 1994, pp. 319.

13. Shukla.S.K, N.B.Singh, R.P.Rastogi, Indian Journal of Engg and Materials Sciences, 20, 2013, pp $319-324$.

14. Cullity. B. D, "Elements of X-Ray Diffraction," Addison - Wesley, Reading, 2005.

15. Kondawar, S. B, S.P. Agrawal, S.H. Nimkar, H.J. Sharma, P.T. Patil, Adv. Mat. Lett. 2012, 3(5), 393.

16. Kondawar, S.B. S.A. Acharya, S.R. Dhakate, Adv. Mat. Lett. 2011, 2(5), 362.

17. Shukla, S. K, A. Tiwari, Advanced Materials Research, 2011, 306-307, 82.

18. Tiwari, A, R.Kumar, M.Prabaharan, R.R. Pandey, P. Kumari, A. Chaturvedi, A.K. Mishra, Polymers for Advanced Technologies, 2010, 21, 615.

19. Ansari, S. P, F. Mohammad, "Electrical studies on the composite of polyaniline with Zinc oxide nanoparticles," The IUP Journal of Chemistry, vol. 4, pp. 7-18, 2010.

20. Shahid Pervez Ansari and Faiz Mohammad, ISRN Materials Science, 2012, Vol 129869 7pages.

21. Sanjay L. Patil1, Manik A. Chougule, Shailesh G. Pawar, Shashwati Sen, Vikas B. Patil, Soft Nanoscience Letters, 2012, 2, 46-53.

22. Subhash B. Kondawar*, Pallavi T. Patil, Shikha P. Agrawal, Adv. Mat. Lett. 2014, 5(7), 389-395.

23. Amrut S. Lanje, Satish J. Sharma, S. Raghumani, J. Ningthoujam, S. Ahn, Ramchandra B. Pode. 